Article

\title{
The Influence of Different Pre-Treatments of Concrete Surface on the Bond Strength of Geopolymer-Type Coating Layer
}

\begin{abstract}
Alena Sicakova
Institute of Environmental Engineering, Faculty of Civil Engineering, Technical University of Kosice, 04200 Kosice, Slovakia; alena.sicakova@tuke.sk; Tel.: +421-55-602-4275

Received: 7 October 2018; Accepted: 1 November 2018; Published: 5 November 2018

check for updates

Abstract: The treatment of concrete surface using more durable material is one way to slow down the damage process of material, which can negatively affect durability of construction. This paper is aimed at testing the geopolymer-type coating materials of different composition while placing emphasis on various techniques of surface pre-treatments of concrete to which they were applied. The main composition variables were as follows: the fly ash fineness (original, ground) and the addition of washing-aggregate sludge. Four compositions were tested and compared with the composition based on cement binder. The cement mixture was prepared using the same fillers. The following techniques of surface pre-treatment of concrete were applied: brushing, pressure washing, and pressure washing followed by penetration, together with non-treated surface being used for comparison. The effect of the surface treatment technique was tested through the adhesion strength, which was executed at 2, 7,28, and 120 days after application of the coating. The influence of the composition of geopolymer coating material was also discussed. Geopolymer-based mixtures achieved better adhesive strength than the cement-based mixture, regardless of surface treatment technique. The addition of sludge microfiller seems to be beneficial in improving the adhesive strength of geopolymer-type coating material.
\end{abstract}

Keywords: concrete surface; geopolymer; fly ash; washing aggregate sludge; surface pre-treatment; bond strength

\section{Introduction}

The surfaces of many of the concrete structures are subject to deterioration due to freezing and thawing, penetration of solutions, weathering, chemical attack, and erosion. Surface resistance of concrete is becoming one of the significant aspects of the service life of concrete structures, which defines sustainability of structure. Surface deteriorations could develop into structural problems, especially in reinforced concrete structural elements [1]. The most effective way to reduce this damage is to prevent the ingress of fluid into the concrete, so as to prevent the penetration of aggressive chemicals. The treatment of concrete surface using more durable material is one way to slow down the damage process.

Geopolymers are a type of inorganic polymer that can be formed at room temperature by using industrial waste/by-products as source materials to form a solid binder that looks like and performs similarly to Ordinary Portland Cement (OPC) [2]. Interest in geopolymer is still increasing due to its benefits compared to OPC. Geopolymers are referred to as possessing the following characteristics: abundant raw materials resources, energy saving and environment protection due to low energy consumption, thermal processing (if necessary) at relatively low temperature as well as due to little $\mathrm{CO}_{2}$ emission, simple preparation technique, good volume stability, reasonable strength gain in a short time, ultra-excellent durability, high fire resistance and low thermal conductivity [3]. 
Low-calcium (Class F) fly ash is preferred as a source material compared to high-calcium (Class C) fly ash. According to [2], the low calcium fly ash-based geopolymer manufactured with different activators have shown high compressive strengths and excellent performance when exposed to different acid and sulphate solutions. It has also been reported to be highly resistant to elevated temperatures [4].

The washing-aggregate sludge, also called quarry washings, is retained after the sorting and washing process of the crushed aggregates. Its composition is usually unguaranteed, which in fact is a hindrance to its wider use in building materials. According to [5], crushed rock fines have the potential to be incorporated into brick manufacture or cement production.

Basically, coating is applied to the surface of an object or substrate to improve its surface properties, like appearance, adhesion, wettability, corrosion resistance, wear/scratch resistance, and also the thermal resistance. In addition to extending the service life, application of coating also reduces the maintenance costs of the existing structure [6]. The coating used for surface protection should allow the concrete to breath; otherwise, the coating tends to delaminate due to the collection of liquid at the interface. This had necessitated the development of inorganic coatings, which will allow the concrete to breathe [1]. As for coating methods, several techniques can be used such as dipping [7], spraying [8] and painting [9]. The American Concrete Institute [10] defines coatings as materials applied to a surface by brushing, dipping, mopping, spraying, trowelling, etc. to preserve, protect, decorate, seal, or smoothen the substrate.

For coating application, the adhesive strength of the coating to substrate is very important in achieving the highest value in order to improve anticorrosion, fire and heat resistance, hardness as well as extending the service life of the material. When considering the geopolymer-type material, this is believed to be strongly influenced by its formulation [7]. Temuujin et al. [8] have also shown that the best adhesive strength observed was for high silica containing composition ( $\mathrm{Si}: \mathrm{Al}=3.5$ ratio) with a pressure higher than $3.5 \mathrm{MPa}$, and, to achieve a greater fire insulating capacity, the coating thicknesses should be increased. It can be summarized that the optimal condition of the concrete surface, expressed through the adhesion strength, depends on the following:

- the type/properties of coating material,

- the condition of the substrate, depending on its treatment (concrete surface preparation),

- way/technique of coating application.

Concrete surfaces that are used as substrates may cause problems that are not necessarily present with other materials including [11]:

- Concrete surfaces are often very rough and have partly open air voids.

- Concrete surfaces are adsorbent to varying degrees.

- Concrete surfaces may be dusty and friable.

- Formed and floated surfaces commonly have a thin and relatively weak layer (laitance).

- Formed surfaces can contain significant amounts of adhered release agent.

This is why, before applying the coating, these shortcomings should be eliminated by the surface treatment. The methods for surface preparation are generally as follows [12]: chemical cleaning, mechanical cleaning (using the impact tools, scabblers, scarifiers), blast cleaning (sandblasting, both wet and dry, shot blasting, and waterjet cleaning) and acid etching. These result in different surface quality.

As given in [6], Temuujin et al. [8] found that the fly ash-geopolymer sample which is coated onto polished mild steel showed an adhesive strength of $2.7 \mathrm{MPa}$, which is $0.5 \mathrm{MPa}$ lower than non-polished mild steel substrate, indicating that surface roughness influences adhesion strength. As for concrete surfaces, Balaguru [1] suggests that the geopolymer coating is applicable to smooth or rough surfaces with minimal surface preparation. Only excess dirt and standing water need to be removed before the application. 
This paper is aimed at testing the geopolymer-type coating materials of different composition while emphasizing various techniques of surface pre-treatments of concrete to which they were applied. The main composition variables were as follows: the fly ash (FA) fineness (original, ground) and the addition of washing-aggregate sludge. Four compositions were tested and compared with the composition based on the cement binder. The cement mixture was prepared using the same fillers. The following techniques of surface pre-treatment of concrete were applied: brushing, pressure washing, and pressure washing followed by penetration, together with non-treated surface being used for comparison. The effect of the surface treatment technique was tested through the adhesion strength, which was executed at 2, 7, 28, and 120 days after the coating application. The influence of the composition of geopolymer coating material was also discussed.

The experiment was intended as an environmental support in terms of both the utilization of specific/regional kinds of waste (low-calcium type of FA, ground granulated blast furnace slag, and washing aggregate sludge) and the improvement of concretes' surface parameters for longer service life. There is little data on how the type of surface preparation influences the adhesion properties of a coating as far as it is a geopolymer-type material. Moreover, the time development of the adhesion strength, starting from very early age up to 120 days, is considered to be valuable from the technological point of view.

\section{Materials and Methods}

For the coating of concrete surface, the geopolymer-type material was chosen. For comparison, cement-based mixture was also tested. The materials for tested coating mixtures were as follows:

- Original fly ash: OT-FA (coming from Heating plant, class F) and

- Ground fly ash: GT-FA—as a basic component of geopolymer,

- ground granulated blast furnace slag: GGBFS (Steel making factory, Slovakia)—as an intensificator,

- $\mathrm{Na}_{2} \mathrm{SiO}_{3}+\mathrm{NaOH}$-as an activator,

- washing-aggregate sludge: WAS - the material from processing (washing) the crushed aggregates, obtained from an Eastern Slovakia producer of crushed aggregates. After the separation of portion, $<125 \mu \mathrm{m}$ was applied as microfiller.

- $\quad$ ordinary Portland Cement-OPC (CEM I 42.5 R, Slovakia)—as a binder

- tap water,

- admixture-the plasticizer to improve the consistency of mixtures.

Table 1 presents the chemical composition of OT-FA, GT-FA, GGBFS, WAS and OPC. The parameter of grain size distribution is also given by distribution values on the $x$-axis $\mathrm{d}_{(0.1)}$ (the size of particle for which $10 \%$ of the sample is below this size), $d_{(0.5)}$ - median and $d_{(0.9)}$ (the size of particle for which $90 \%$ of the sample is below this size), and by the mean value $\mathrm{dm}$. To find these parameters, the technique of laser diffraction was used, based on measuring the intensity of light scattered as a laser beam passes through a dispersed particulate sample (Malvern Mastersizer, Malvern Instruments Ltd., UK, 2000).

Table 1. Chemical composition and grain size distribution parameters of input materials.

\begin{tabular}{cccccccccc}
\hline \multirow{2}{*}{ Materials } & \multicolumn{4}{c}{ Oxide Composition (\%) } & \multicolumn{5}{c}{ Parameters of Grain Size Distribution $(\mu \mathrm{m})$} \\
\cline { 2 - 10 } & $\mathbf{S i O}_{\mathbf{2}}$ & $\mathbf{C a O}$ & $\mathbf{M g O}$ & $\mathbf{F e}_{\mathbf{2}} \mathbf{O}_{\mathbf{3}}$ & $\mathbf{A l}_{\mathbf{2}} \mathbf{O}_{\mathbf{3}}$ & $\mathbf{d}_{(\mathbf{0 . 1})}$ & $\mathbf{d}_{(\mathbf{0 . 5})}$ & $\mathbf{d}_{(\mathbf{0 . 9})}$ & $\mathbf{d}_{\mathbf{m}}$ \\
\hline OT-FA & 51.11 & 2.58 & 1.18 & 6.40 & 23.21 & 3.97 & 20.44 & 84.73 & 74.10 \\
GT-FA & 49.72 & 2.49 & 1.09 & 6.37 & 22.32 & 3.48 & 14.53 & 52.81 & 31.02 \\
GGBFS & 41.28 & 35.98 & 12.85 & 0.39 & 6.30 & 3.61 & 19.03 & 111.5 & 49.46 \\
OPC & 19.87 & 64.36 & 4.61 & 3.18 & 3.99 & 3.20 & 17.69 & 49.57 & 29.90 \\
WAS $<125 \mu \mathrm{m}$ & 42.66 & 5.83 & 5.04 & 6.54 & 11.19 & 17.49 & 82.50 & 149.8 & 83.55 \\
\hline
\end{tabular}


As for fly ash (OT-FA), the influence of fine-grain form was tested. For this purpose, the results of the previous experiment, which were focused on finding the grinding conditions for reducing its particle size, were considered [13]. Accordingly, the sample prepared by the following grinding conditions was selected for this experiment: grinding time of $60 \mathrm{~min}$ and grist:grinding media proportion: 2:1. The mean size $d_{m}$ was reduced by grinding from 74.1 to $31.02 \mu \mathrm{m}$, which is practically the mean size of cement particles. The chemical composition of OT-FA was in the range of values for class $\mathrm{F}$ flay ash; the calcium oxide content was less than $8 \%$ (2.58), and $\mathrm{SiO}_{2}+\mathrm{Al}_{2} \mathrm{O}_{3}+\mathrm{Fe}_{2} \mathrm{O}_{3}$ was above $70 \%$ (80.7).

The sludge (WAS) was withdrawn from the dewatering pond and dried, after which a portion $<125 \mu \mathrm{m}$ was separated using standard sieve. The aim was to obtain a micro-filler. The value of $\mathrm{d}_{(0.9)}=149.8 \mu \mathrm{m}$ was from the accuracy limit of such a mechanical process. However, the material can be classified as having $\mathrm{d}_{\mathrm{m}}=83.55 \mu \mathrm{m}$.

Table 2 illustrates the principle of the tested mixture's composition. For mixtures T1-T3 (geopolymer pastes), the FA is intended to be a basic geopolymer filler, while the unground and ground forms are used in three combinations. Mixtures T4 and T5 (mortars) contain ground FA only (GT-FA), while 30\% is replaced by sludge microfiller (WAS). As for these two mixtures, the difference lies in the binding principle: T4 is based on geopolymer reaction similar to the previous mixtures, while $\mathrm{T} 5$ contains cement binder only and is considered as a comparative sample.

The geopolymer mixtures were designed according to the compositions listed in [3,14-17]-the actual values are given in Table 3. Alkaline-activating agent for mixtures T1-T4 was prepared by mixing $\mathrm{Na}_{2} \mathrm{SiO}_{3}$ and $\mathrm{NaOH}$. The $\mathrm{SiO}_{2}$ to $\mathrm{Na}_{2} \mathrm{O}$ ratio $\left(\mathrm{M}_{\mathrm{S}}\right.$ Modulus) in the alkaline activating agent was adjusted by addition of $8 \mathrm{M} \mathrm{NaOH}$ to $\mathrm{Na}_{2} \mathrm{SiO}_{3}$ with a $\mathrm{M}_{\mathrm{s}}=2.5$.

Table 2. The composition of experimental mixtures.

\begin{tabular}{ccccccc}
\hline \multirow{2}{*}{ Materials } & & \multicolumn{4}{c}{ Mixtures } \\
\cline { 2 - 6 } & & T1 & T2 & T3 & T4 & T5 \\
\hline \multirow{2}{*}{ Composition of fillers $(\%)$} & GT-FA & 100 & 50 & - & 70 & 70 \\
& OT-FA & - & 50 & 100 & - & - \\
& WAS $<125 \mu \mathrm{m}$ & - & - & - & 30 & 30 \\
\hline Indication of presence of other components $(\bullet)$ & GGBS $(20 \%$ of FA) & $\bullet$ & $\bullet$ & $\bullet$ & $\bullet$ & - \\
& Na2SiO3 & $\bullet$ & $\bullet$ & $\bullet$ & $\bullet$ & - \\
& OM NaOH & $\bullet$ & $\bullet$ & $\bullet$ & $\bullet$ & - \\
& Water & - & - & - & - & $\bullet$ \\
\hline
\end{tabular}

Table 3. Parameters of experimental mixtures.

\begin{tabular}{|c|c|c|c|c|c|c|c|}
\hline & \multirow{3}{*}{ Parameters } & \multicolumn{6}{|c|}{ Values of Parameters } \\
\hline & & \multirow{2}{*}{ According to References } & \multicolumn{5}{|c|}{ Tested Mixtures } \\
\hline & & & T1 & T2 & T3 & $\mathrm{T} 4$ & T5 \\
\hline 1 & Water from the alkaline activators/geopolymer solids & 0.19 & 0.19 & 0.19 & 0.19 & 0.25 & / \\
\hline 2 & Alkaline solution/FA & $0.25-0.45$ & 0.38 & 0.38 & 0.38 & 0.56 & / \\
\hline 3 & $\mathrm{Na} 2 \mathrm{SiO} 3 / \mathrm{NaOH}$ & $1-1.25$ & 1.18 & 1.18 & 1.18 & 1.18 & / \\
\hline 4 & Water/solids & $0.23-0.51$ & 0.24 & 0.26 & 0.30 & 0.33 & 0.37 \\
\hline
\end{tabular}

The properties of geopolymer mixtures were presented in [18], showing the 28-day flexural and compressive strength ranging from 1.6 to $3.9 \mathrm{MPa}$, and 5.0 to $16.0 \mathrm{MPa}$, respectively. The emphasis of the actual experiment was placed on various techniques of base-surface treatments of concrete element before the application of coating layer. For this purpose, the concrete plates $(300 \times 300 \times 100 \mathrm{~mm})$ 
were prepared in laboratory conditions, using standard composition $\left(D_{\max }=16 \mathrm{~mm}\right.$, CEM I 42.5 $\left.\mathrm{N}-330 \mathrm{~kg} / \mathrm{m}^{3}, \mathrm{w}=0.55\right)$. The following surface treatment techniques were applied:

- $\quad$ brushing (B) with a wire brush: the purpose of this process was to roughen the surface.

- pressure washing (PW): the aim was to remove the thin layer of cement milk and roughen the surface. The pressure washer was used for this purpose.

- $\quad$ pressure washing followed by penetration $(\mathrm{PW}+\mathrm{P})$ : standard acrylate type penetrator.

- $\quad$ non-treated surface (0)-it was used as a reference surface.

Preparation of concrete plates: the concrete plates were divided into four groups according to respective surface treatment. When demolded after $24 \mathrm{~h}$, both the brushing and pressure washing were performed for samples $\mathrm{B}, \mathrm{PW}$ and $\mathrm{PW}+\mathrm{P}$. The plates were then cured in wet conditions, together with non-treated plates (0). The surface coatings were applied on $28( \pm 3)$ days of curing. To apply the surface coating, the plates were removed from water two days before and they have been left in laboratory conditions $\left(20^{\circ} \mathrm{C}\right.$ and $\left.50 \% \mathrm{RH}\right)$. In the case of $\mathrm{PW}+\mathrm{P}$ treatment, the plates were removed from water four days before, and, after two days, the penetration was performed.

The surface-coating performing: the coating layer was applied with a brush, while controlling for $0.5 \mathrm{~mm}$ thickness. Samples were then covered by plastic sheets and kept for up to seven days (in case of two-day measurements only up to this time), then stored under laboratory conditions $\left(20^{\circ} \mathrm{C}\right.$ and $50 \% \mathrm{RH})$ up to testing time.

The measurements of bond strength: they were executed after 2, 7, 28 and 120 days of application of coating layer, using the bond test according to [19]. In the bond test, the groove is first drilled through the coating layer into the concrete base. Then, a disc is bonded to a prepared testing surface and the disc is pulled off. The pull-off force, F, is divided by the cross-sectional area of the partial core to obtain the bond strength $\sigma_{\text {adh }}$ :

$$
\sigma_{\mathrm{adh}}=\frac{4 F}{\pi d^{2}}
$$

where $\mathrm{d}$ is the diameter of the partial core.

Each result is a mean value of three measurements, while only a satisfactory failure type ("failure in substrate" and "bond failure") was taken into account.

\section{Results and Discussion}

The results of tests on adhesive strength are reported in the following figures. For discussion of the mentioned properties, the results are summarized in the graphs, which are organized into two groups:

- $\quad$ Results according to technique of surface treatment: Figures 1,3,5 and 7.

- Results according to type of coating material: Figures 2, 4, 6, 8 and 9.

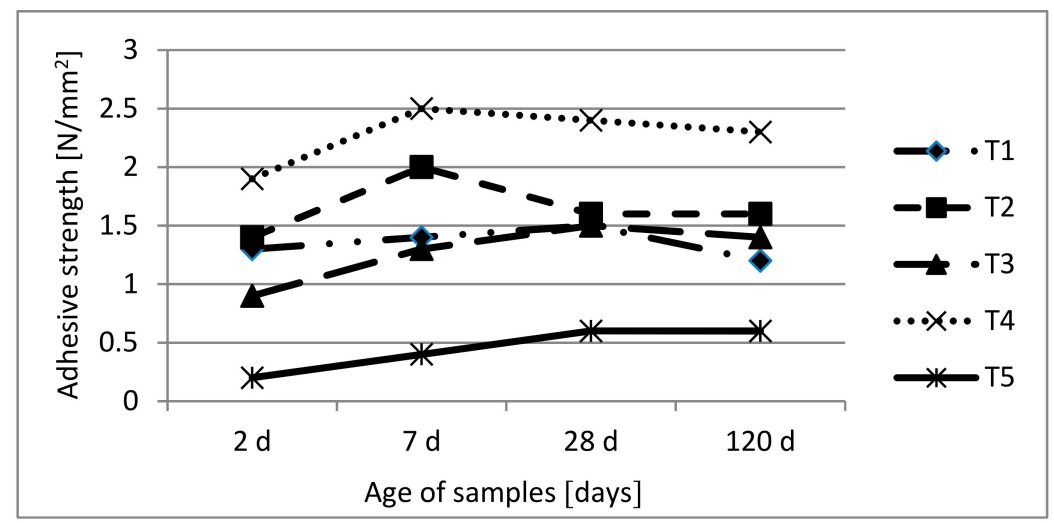

Figure 1. Adhesive strength of coating materials T1-T5: non-treated surface (0). 


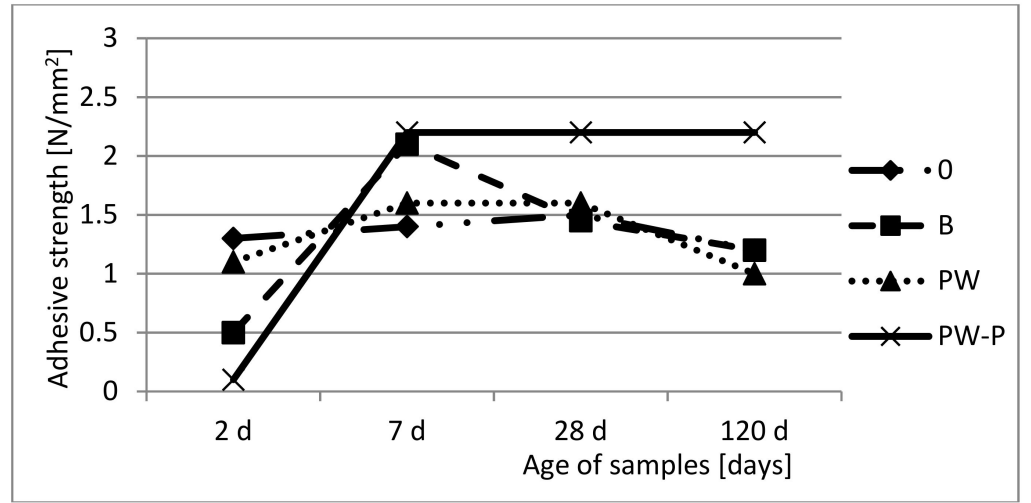

Figure 2. Adhesive strength of coating material T1 depending on the surface treatment.

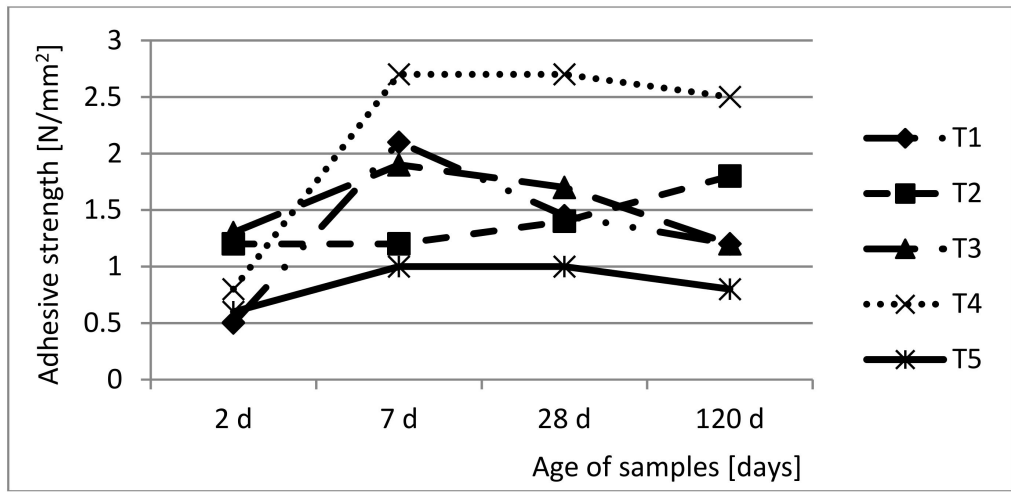

Figure 3. Adhesive strength of coating materials T1-T5: brushed surface (B).

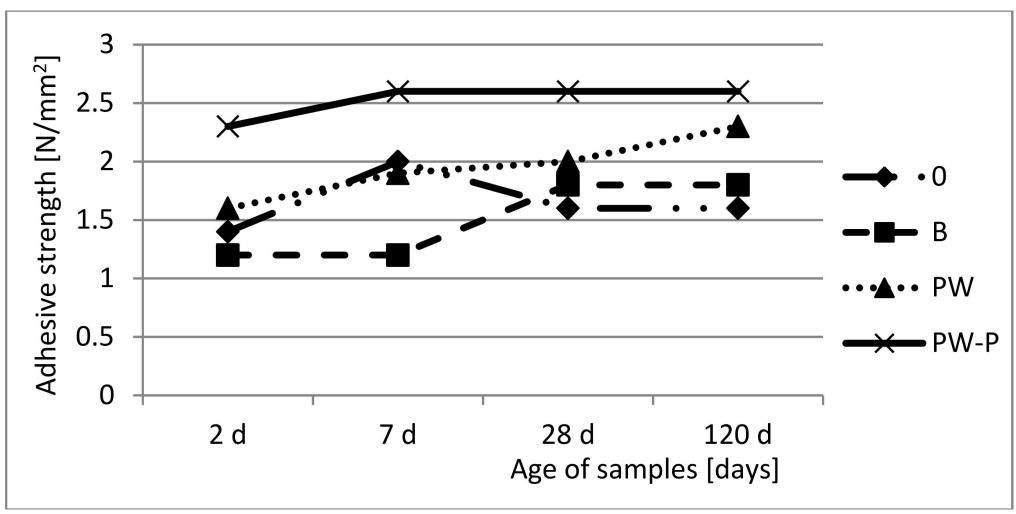

Figure 4. Adhesive strength of coating material T2 depending on the surface treatment.

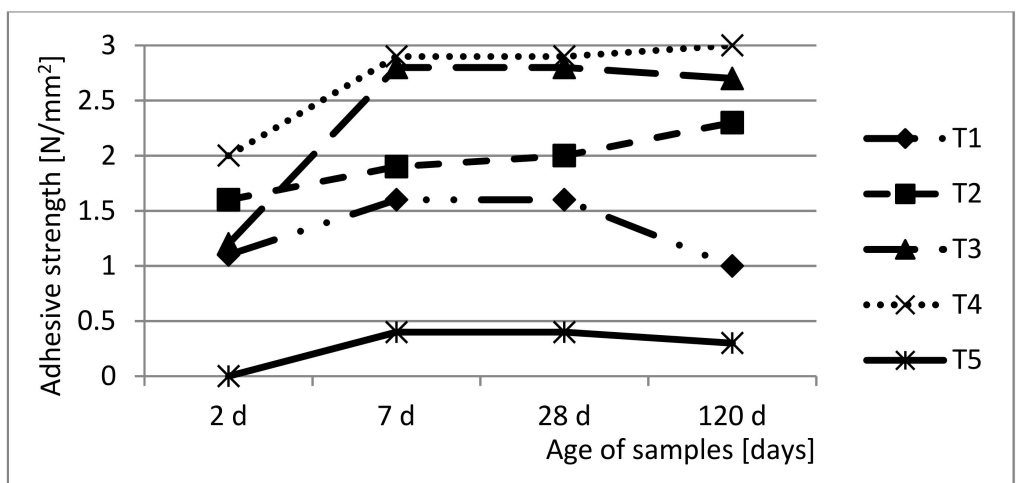

Figure 5. Adhesive strength of coating materials T1-T5: pressure washed surface (PW). 


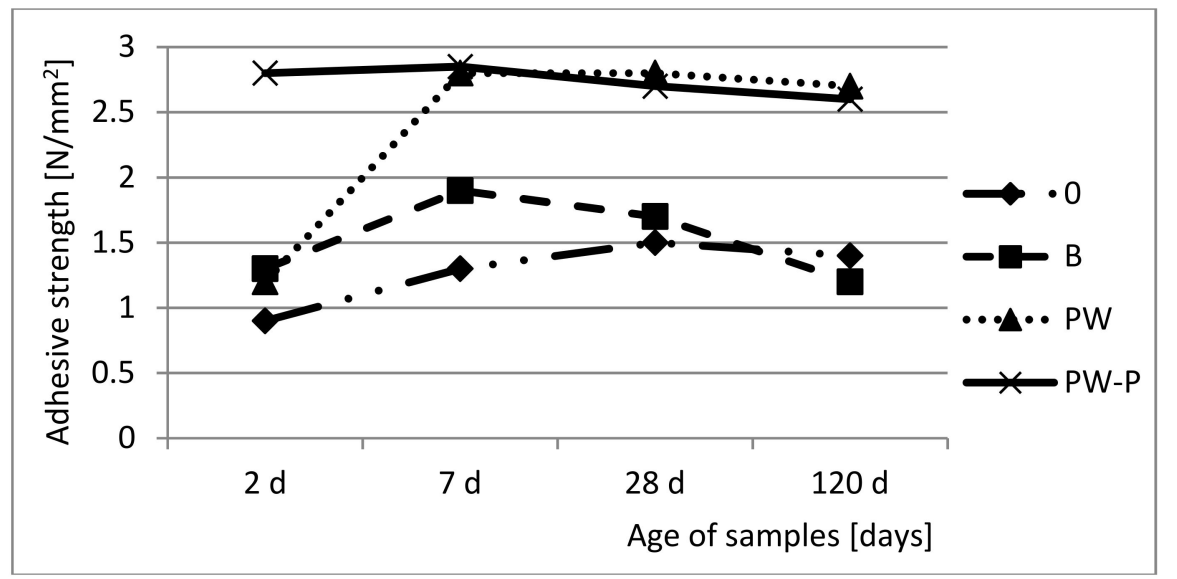

Figure 6. Adhesive strength of coating material T3 depending on the surface treatment.

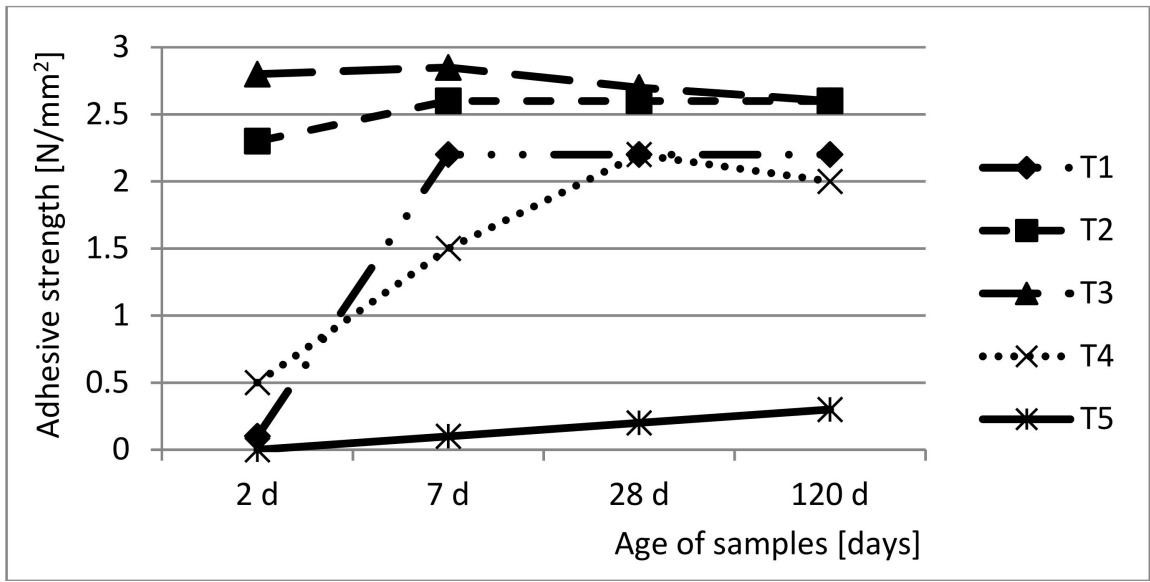

Figure 7. Adhesive strength of coating materials T1-T5: pressure washed surface followed by penetration (PW-P).

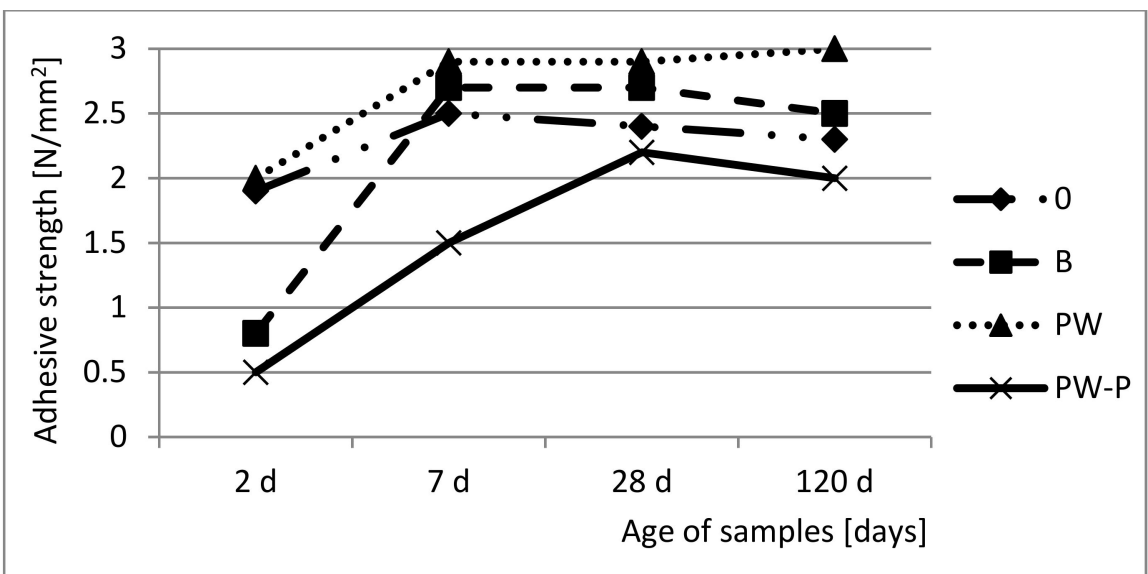

Figure 8. Adhesive strength of coating material T4 depending on the surface treatment. 


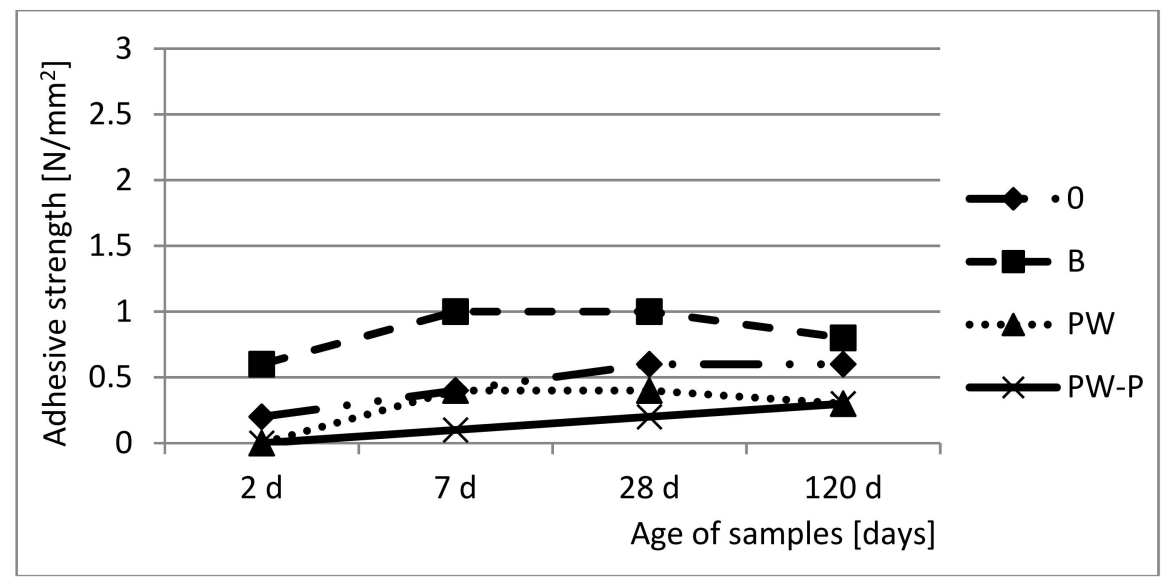

Figure 9. Adhesive strength of coating material T5 depending on the surface treatment.

\subsection{Results According to Technique of Surface Treatment}

There are several requirements for the values of adhesive strength of coatings, depending on its actual function. As given in [20], the values should range from $0.8 \mathrm{~N} / \mathrm{mm}^{2}$; the most common limit is $1.5 \mathrm{~N} / \mathrm{mm}^{2}$ at least.

All tested surfaces allowed the achievement of high 28-day values of adhesive strength (between 2.0-3.0 N/ $\mathrm{mm}^{2}$ ); however, when using both the untreated and brushed surface, this was only possible with the T4 mixture. The pressure-wash treated surfaces (PW and PW-P) were more universal; they allowed almost all geopolymer mixtures (T1-T4) to reach values above $2.0 \mathrm{~N} / \mathrm{mm}^{2}$. The only exception was PW with T1; however, this is also a good practical value $>1.5 \mathrm{~N} / \mathrm{mm}^{2}$.

Looking at Figures 1, 3, 5 and 7, it is clear that sample T5 (cement-based mixture) achieved the lowest values of adhesive strength regardless of surface treatment technique. In the case of surfaces, PW and PW-P, the difference to other coating materials was even more significant since the adhesive strength of sample T5 did not exceed the value $0.5 \mathrm{~N} / \mathrm{mm}^{2}$. It is probably due to the very thin layer, which is susceptible to rapid drying even though it has been cured by covering. This seems to be insufficient for a proper hydration process, which would result in the formation of the hydration products required to form a bond between the substrate and the coating. O'Dea and Schwab [21], who tested the bond strength of various cementitious resurfaces (Portland-based, epoxy modified, acrylic modified and calcium aluminate-based), also suggested that Portland-based coating mortars seem to be weakest even if proper curing and surface precautions were followed. He also highlights that special care should be followed when applying Portland-based cementitious resurfaces for thin patch repairs. In addition, Fiebrich [22] concluded that ordinary cement mortar repair materials often led to increased shrinkage stress on the interface and resulted in greater deformation of interface and bond failure. Better performance of geopolymer coatings is presented also by Papakonstantinou and Balaguru [23], who state that unlike organic coatings, geopolymer coatings are permeable to vapor pressure and thus do not delaminate from the parent surface.

The mixture having the best position within the individual surfaces is the T4 (geopolymer mixture containing washing-aggregate sludge microfiller), except for the PW-P surface treatment. Thus, the addition of WAS microfiller seems to be beneficial for adhesive strength of the geopolymer coating material. For the PW-P surface treatment, the T3 material seems to be the best. Comparing only samples T1-T3 (geopolymer pastes that differ in the portion of unground/unground fly ash), the order in standard 28 days is as follows (starting with the best):

- $\quad$ Surface 0: T2, T1, T3.

- $\quad$ Surface B: T3, T1, T2.

- $\quad$ Surface PW: T3, T2, T1.

- $\quad$ Surface PW-P: T3, T2, T1. 
Although the values within the same surface are close to each other with no significant difference (except the values at PW surface), the T3 material (based on unground fly ash) takes the lead-it points to the better performance of unground fly ash for the adhesive strength. Some research works have dealt with the effect of fly ash fineness on the compressive strength of geopolymer mixtures [18,24,25], referring generally to the significant contribution of the fineness to the compressive strength of the geopolymer mortar. However, there is a lack of results on the effect on adhesive strength.

Evaluating the time development of adhesive strength, there is a clear increasing tendency for all surfaces, as well as coating materials, but mostly only up to 7 or 28 days; then, a decrease was observed. There are few exceptions here, implying the increase of adhesive strength in 120 days: surface 0 and coating T5, surface B and coating T2, surface PW and coatings T2 and T4, surface PW-P and coatings $\mathrm{T} 2$ and T4. Thus, the T2 material seems to be the best generally for all treated surfaces from the point of view of maintaining the increasing tendency of adhesive strength. These findings are in agreement with those referring to the need of pre-treatment of the concrete surfaces [12], as it influences the adhesive strength of the coating layer.

\subsection{Results According to the Type of Coating Material}

Looking at the performance of individual coating materials on the individual kinds of surfaces, the following points can be highlighted:

- Coating material T1 shows good performance as far as it is used on the PW-P surface. Here, the balanced values of adhesive strength were measured on time $\left(2.0 \mathrm{~N} / \mathrm{mm}^{2}\right)$. Once other surfaces are used, the values decrease after 28 days. The 28 -day values between 1.4 and $2.2 \mathrm{~N} / \mathrm{mm}^{2}$ were achieved.

- Coating material T2 gives quite a balanced performance on all surfaces; however, it is the best on the PW-P surface. The 28-day values between 1.6 and $2.6 \mathrm{~N} / \mathrm{mm}^{2}$ were achieved.

- Coating material T3 shows the best performance when PW and PW-P surfaces are used-the adhesive strength is $2.8 \mathrm{~N} / \mathrm{mm}^{2}$ and $2.7 \mathrm{~N} / \mathrm{mm}^{2}$, respectively.

Thus, for adhesive strength of geopolymer pastes T1-T3, the PW-P surface treatment seems to be the best, while non-treated surface (0) allows for achieving the worst one in most cases. The difference between 28-day strength values of pastes T1-T3 when applied on PW-P and 0 surface are 0.6, 1.0 and 1.2 $\mathrm{MPa}$, respectively. Within the strength values achieved in this experiment, this is a significant difference. Unlike Balaguru [1], who suggests that the geopolymer coating is applicable to smooth or rough surfaces with minimal surface preparation, the surface treatment prior to the geopolymer coating application seems to be important.

- Coating material T4 shows the most significant increase in values from 2 to 28 days. The values in 28 days are balanced, ranging between 2.2 and $2.9 \mathrm{~N} / \mathrm{mm}^{2}$. This material shows the best performance when used on the PW surface.

- Coating material T5 shows the lowest values of all samples. This material shows the best performance when used on the B surface; however, the range of results (not exceeding the $1.0 \mathrm{~N} / \mathrm{mm}^{2}$ at any given time, as well as on any surface) allows for concluding that the kind of surface treatment does not provide for significant differences in adhesive strength. This is in line with [26], who showed that increasing the contact area in the substrate, as a result of different surface textures, does not always increase the bonding strength between the substrate and the render. The results of $\mathrm{T} 5$ do not provide a basis for practical use.

\section{Conclusions}

This paper was focused on the utilization of regional alternative (waste) materials (low-calcium fly ash, ground granulated blast furnace slag, and washing aggregate sludge) as components of a standard geopolymer mixture. Five mixtures were tested: T1-T3 (geopolymer pastes where the FA is 
intended to be a basic geopolymer filler, while the unground and ground forms were used in three combinations), and mixtures T4-T5 (mortars containing ground FA only, while $30 \%$ were replaced by a sludge microfiller with differing binding principle: $\mathrm{T} 4$ was based on geopolymer reaction while the $\mathrm{T} 5$ contained cement binder only). The emphasis of the experiment was placed on various techniques of base-surface treatments of concrete element before the application of coating layer. The following surface treatment techniques were applied: brushing (B) with a wire brush, pressure washing (PW), pressure washing followed by penetration $(\mathrm{PW}+\mathrm{P})$, and a non-treated surface $(0)$ was used for comparison. The following can be summarized:

- All tested surfaces enabled the achievement of the 28-day values of adhesive strength between 2.0-3.0 N/ $\mathrm{mm}^{2}$, which fulfill the usual limit $\left(1.5 \mathrm{~N} / \mathrm{mm}^{2}\right.$ minimum). However, when using both the untreated and brushed surface, one kind of coating material can possibly be used (the T4 mixture).

- The pressure-wash treated surfaces (PW and PW-P) were more universal; they allowed almost all geopolymer mixtures (T1-T4) to reach values above $2.0 \mathrm{~N} / \mathrm{mm}^{2}$

- Geopolymer-based mixtures achieved better adhesive strength than that of cement-based mixture, regardless of surface treatment technique. Among them, sample T4 reached the best values (in three out of four cases of pre-treated surfaces); thus, the addition of sludge microfiller seems to be beneficial for improving the adhesive strength of geopolymer-type coating material.

- For the best performance, the appropriate kind of mixture (coating material) has to be assigned to the particular surface pre-treatment technique.

- Time development of adhesive strength showed increasing tendency for all surfaces, as well as coating materials, but mostly only up to 7 and 28 days, respectively; then, the decrease was detected. On the basis of a few exceptions that have been observed, it is possible to specify $\mathrm{T} 2$ material to be the best for all treated surfaces in terms of maintaining the increasing time development of adhesive strength.

Funding: This research has been carried out within the project NFP 26220220051 "Development of progressive technologies for utilization of selected waste materials in road construction engineering", supported by the European Union Structural funds and within the project of Slovak Scientific Grant Agency VEGA (Grant No. 1/0524/18).

Conflicts of Interest: The author declares no conflicts of interest

\section{References}

1. Balaguru, P.N. Geopolymer Coating Demonstration Project for Route I-295 Scenic Overlook. In Report, Center for Advanced Infrastructure \& Transportation (CAIT); The State University: Rutgers, NJ, USA, 2006.

2. Thokchom, S.; Dutta, D.; Ghosh, S. Effect of Incorporating Silica Fume in Fly Ash Geopolymers. World Acad. Sci. Eng. Technol. 2011, 60, 243-247.

3. Zongjin, L.; Zhu, D.; Yunsheng, Z. Development of Sustainable Cementitious Materials. In Proceedings of the International Workshop on Sustainable Development and Concrete Technology, Beijing, China, 20-21 May 2004; Iowa State University: Ames, IA, USA, 2004.

4. Kong, D.L.Y.; Sanjayan, J.G. Effect of elevated Effect of elevated temperatures on geopolymer paste, mortar and concrete. Cem. Concr. Res. 2010, 40, 334-339. [CrossRef]

5. Cresswell, D. Quarry Fines \& Paper Sludge in Manufactured Aggregate. In Case Study WRT 177/WR0115; Smart Waste: London, UK, 2016.

6. Salwa, M.S.; Al Bakri, A.M.; Kamarudin, H.; Ruzaidi, C.M.; Binhussain, M.; Zaliha, S.S. Review on Current Geopolymer as a Coating Material. Aust. J. Basic Appl. Sci. 2013, 7, 246-257.

7. Temuujin, J.; Minjigmaa, A.; Rickard, W.; Lee, M.; Williams, I.; Van Riessen, A. Preparation of Metakaolin Based Geopolymer Coatings on Metal Substrates as Thermal Barriers. Appl. Clay Sci. 2009, 46, 265-270. [CrossRef]

8. Temuujin, J.; Minjigmaa, A.; Rickard, W.; Lee, M.; Williams, I.; Van Riessen, A. Fly Ash Based Geopolymer Thin Coatings on Metal Substrates and Its Thermal Evaluation. J. Hazard. Mater. 2010, 180, 748-752. [CrossRef] [PubMed] 
9. Balaguru, P.N.; Nazier, M.; Arafa, M. Field Implementation of Geopolymer Coatings. In Report, Center for Advanced Infrastructure \& Transportation (CAIT); The State University: Rutgers, NJ, USA, 2004.

10. Guide to Selecting Protective Treatments for Concrete; 515.2R-13; American Concrete Institute: Farmington Hills, MI, USA, 2013.

11. Benn, B.T. The Influence of Curing and Surface Preparation on the Adhesion of Protective Coatings on Concrete. In The Research Report, Faculty of Engineering and the Built Environment; University of the Witwatersrand: Johannesburg, South Africa, 2008.

12. Mailvaganam, N.P.; Pye, G.B.; Arnott, M.R. Surface Preparation of the Concrete Substrate. In Construction Technology Updates; Institute for research in construction, National Research Council of Canada: Ottawa, ON, Canada, 1998.

13. Želinková, M. The Analysis of Particle Size of Fly Ashes-The Possibility of Obtaining Fine Particles by Grinding. In Proceedings of the Ph.D. Students Seminar, Tromsø, Norway, 13-15 October 2014; TU Kosice: Košice, Slovakia, 2014.

14. Palomo, A.; Grutzeck, M.W.; Blanco, M.T. Alkali-activated fly ashes-Cement for the future. Cem. Concr. Res. 1999, 29, 1323-1329. [CrossRef]

15. Palomo, A.; Fernández-Jiménez, A. Alkaline Activation, Procedure for Transforming Fly Ash into New Materials. In Proceedings of the World of Coal Ash (WOCA) Conference, Denver, CO, USA, 9-12 May 2011.

16. Yazici, S.; Arel, S. Effects of fly ash fineness on the mechanical properties of concrete. Sadhana 2012, 37, 389-403. [CrossRef]

17. Škvara, F.; Jílek, T.; Kopecký, L. Geopolymer materials based on fly ash. Ceram. Silic. 2005, 49, $195-204$.

18. Sičáková, A.; Števulová, N. Basic physical-mechanical properties of geopolymers depending on the content of ground fly ash and fines of sludge. Sel. Sci. Pap. J. Civ. Eng. 2017, 12, 85-96. [CrossRef]

19. European Committee for Standardization. EN 1542 Products and Systems for the Protection and Repair of Concrete Structures. Test Methods. Measurement of Bond Strength by Pull-of; European Committee for Standardization: Brussels, Belgium, 2001.

20. European Committee for Standardization. 1504-2 Products and Systems for the Protection and Repair of Concrete Structures. Definitions, Requirements, Quality Control and Evaluation of Conformity. Part 2: Surface Protection Systems for Concrete; European Committee for Standardization: Brussels, Belgium, 2005.

21. O'Dea, V.; Schwab, R. Preparing Cementitious Mortars to Support High-Performance Lining Systems. Broom Finish or Blasted Surface; PACE: New Orleans, LA, USA, 2009.

22. Fiebrich, M.H. Scientific Aspects of Adhesion Phenomena in the Interface Mineral Substrate-Polymers. In Proceedings of the 2nd Bolomey Workshop Adherence of young and old Concrete, Sitten, Switzerland, 1 April 1994; Aedificatio Verlag: Unterengstringen, Switzerland, 1994.

23. Papakonstantinou, C.G.; Balaguru, P.N. Geopolymer Protective Coatings for Concrete. In Proceedings of the International SAMPE Symposium and Exhibition, Baltimore, MD, USA, 3-7 June 2007; Volume 52.

24. Firdaus; Yunus, I.; Rosidawani. Contribution of Fineness Level of Fly Ash to the Compressive Strength of Geopolymer Mortar. MATEC Web Conf. 2017, 103, 01026. [CrossRef]

25. Nugteren, H.W.; Butselaar-Orthlieb, V.C.; Izquierdo, M.; Witkamp, G.J.; Kreutzer, M.T. High Strength Geopolymers from Fractionated and Pulverized Fly Ash. In Proceedings of the World of Coal Ash Conference, Lexington, KY, USA, 4-7 May 2009.

26. Stolz, C.M.; Masuero, A.B.; Pagnussat, D.T.; Kirchheim, A.P. Influence of substrate texture on the tensile and shear bond strength of rendering mortars. Constr. Build. Mater. 2016, 128, 298-307. [CrossRef]

(C) 2018 by the author. Licensee MDPI, Basel, Switzerland. This article is an open access article distributed under the terms and conditions of the Creative Commons Attribution (CC BY) license (http://creativecommons.org/licenses/by/4.0/). 